\title{
Терморезистивный полупроводниковый SiC/Si-композиционный материал
}

\author{
(C) С.К. Брантов ${ }^{1}$, Е.Б. Якимов ${ }^{2}$ \\ ${ }^{1}$ Институт фризики твердого тела Российской академии наук, \\ 142432 Черноголовка, Московская область, Россия \\ ${ }^{2}$ Институт проблем технологии микроэлектроники и особочистых веществ Российской академии наук, \\ 142432 Черноголовка, Московская область, Россия \\ E-mail: brantov@issp.ac.ru
}

(Получена 18 июля 2018 г. Принята к печати 27 июля 2018 г.)

Разработан способ непрерывного выращивания слоя самосвязанных кристаллитов карбида кремния на поверхности гибкой углеродной фольги с последующей пропиткой получаемых структур расплавом кремния.

На основе полученного композиционного материала изготовлены терморезисторы для температурного диапазона $900-1450 \mathrm{~K}$ с термочувствительностью, достигающей значения $11350 \mathrm{~K}$, способные использоваться в воздушной среде. Исследованы структурные и электрофизические характеристики упомянутого материала.

DOI: $10.21883 /$ FTP.2019.02.47104.8962

\section{1. Введение}

Систематические литературные данные по проблеме терморезисторов (ТР), использования их в технике и применяемых для их изготовления материалов приведены в работах [1-5]. Традиционно ТР делятся на два типа по знаку температурного коэффициента сопротивления (ТКС): ТР с положительным ТКС (позисторы) изготовлены на основе классических металлов и предназначены в основном для измерения и контроля температуры, тогда как ТР с отрицательным ТКС (термисторы) служат в значительной степени чувствительными датчиками для защиты систем от значительных отклонений режима их функционирования.

Основными параметрами терморезисторов (ТР) являются предельная температура использования и термочувствительность $B=\left(\ln R_{1}-\ln R_{2}\right) /\left(1 / T_{1}-1 / T_{2}\right)$, где $R$ - электросопротивление, $T$ - температура, индексы 1 и 2 соответствуют начальной и конечной точкам термочувствительной области характеристики ТР.

Отдельно следует выделить представляющие особый интерес для техники „переключаемые ТР“ или „ТР с критической температурой $T_{c}$, демонстрирующие резкое снижение электросопротивления в узком температурном интервале, к которым и относятся рассматриваемые в данной работе. Дополнительными требованиями являются повышенная стойкость к нагреву в агрессивных средах, воздействию ионизирующих излучений, а также надежность в эксплуатации.

Для изготовления позисторов используются металлы (в основном медь и платина), для термисторов - полупроводники (в основном $\mathrm{InSb}, \mathrm{Ge}, \mathrm{Si}$ ), а также оксиды марганца и кобальта.

Известны также материалы для термисторов на основе твердых растворов в структуре типа шпинели [6], а также $\mathrm{Bi}_{2} \mathrm{O}_{3}$ в сочетании с другими оксидами [7]. Недостатками этих материалов являются низкие вос- производимость (что требует индивидуальной градуировки) и термочувствительность $B=2850 \mathrm{~K}$, сложность изготовления внешних контактов и невысокая реально достигаемая предельная температура $T=620-870 \mathrm{~K}$. Определенные сомнения вызывает также категорическое отнесение этих материалов к классу полупроводниковых, поскольку из всех знаковых признаков полупроводника безусловно присутствует лишь один: снижение $R$ при увеличении $T$. Более корректным представляется утверждать о наличии признаков полупроводникового поведения у материалов этого класса.

Наиболее близким к предложенному нами является ТР, содержащий термочувствительный элемент $(B=6400 \mathrm{~K})$, выполненный из поликристаллического кремния и не требующий индивидуальной градуировки [8]. Принцип его работы основан на переходе полупроводникового кремния из области примесной проводимости в область собственной при увеличении внешней температуры. Однако по достижении $T=750 \mathrm{~K}$ область термочувствительности этого ТР прекращается.

В данной работе было осуществлено повышение характеристик ТР [8] путем введения в его состав значительного количества полупроводникового карбида кремния.

\section{2. Способ получения композиционного материала}

Базовым промышленным способом получения $\mathrm{SiC}$ из элементов продолжает оставаться способ Ачесона [8] карбоэлектротермического восстановления кремнезема. При его осуществлении источником кремния является двуокись кремния $\mathrm{SiO}_{2}$. Материал, получаемый по процессу Ачесона, пригоден для использования лишь в качестве абразива. Для его применения в приборных структурах необходимо осуществить ряд стадий переработки, 


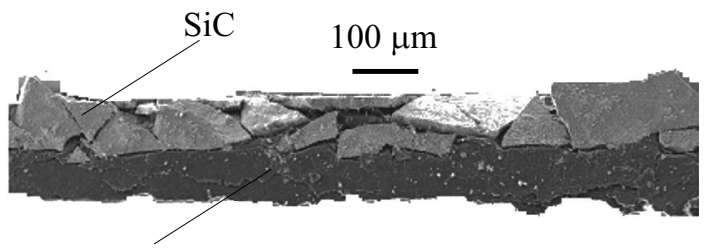

Graphite foil

Рис. 1. Структура слоя самосвязанных кристаллитов $\mathrm{SiC}$, врастающих в исходный материал углеродной фольги (оптическое изображение).

включающих измельчение, деление на фракции, термохимическую очистку и выращивание монокристаллов.

Синтез $\mathrm{SiC}$ по прямой реакции $\mathrm{Si}(\mathrm{L})+\mathrm{C}=\mathrm{SiC}$ позволяет получать композиционные материалы, в составе которых присутствует $\mathrm{SiC}$, но их использование в промышленности возможно лишь в качестве конструкционных изделий или нагревателей [9].

Карбид кремния является перспективным материалом для изготовления приборных структур и защитных покрытий. Наряду с монокристаллами находят применение и поликристаллические пленки $\mathrm{SiC}$ [10-12], но способы их получения достаточно сложны и находятся на лабораторном уровне. Задачей настоящей работы является реализация относительно простого способа получения слоев $\mathrm{SiC}$ полупроводникового уровня чистоты и апробация их в качестве материалов активных элементов термисторов. Разработанный способ подробно описан в работах [13-16].

На первой стадии способа лента из гибкой углеродной фольги перемещается со скоростью до 2.5 м/мин относительно содержащего расплавленный кремний капиллярного графитового питателя, причем в реакционный объем искусственно подается незначительное количество атмосферного воздуха, что инициирует цепь газотранспортных реакций, подробно описанных в $[11,14]$. В результате протекания этих реакций на поверхности фольги непрерывно образуется слой самосвязанных кристаллитов $\mathrm{SiC}$, врастающих в материал фольги с линейной скоростью до $1.5 \mathrm{MM} / \mathrm{c}$, образуя совместно с фольгой двуслойный композит (в дальнейшем $\mathrm{SiC} / \mathrm{C}$-композит). Источником кремния является его моноокись $\mathrm{SiO}$. Вид поперечного среза такого композита приведен на рис. 1. Размеры кристаллитов различаются от долей микрона до 150 мкм, слой имеет электронный тип проводимости, по данным дифракции рентгеновских лучей материал соответствует кубической структуpe „Moissanite-3 $\backslash \mathrm{ITC} \backslash \mathrm{RG}^{\text {“ }}$ с пространственной группой симметрии $F 43 m$ и параметром решетки $a=0.4359$ нм.

Следующей стадией способа является пропитка слоя фольги расплавленным кремнием с целью предотвращения окисления этого слоя при нагреве и получения $\mathrm{SiC} / \mathrm{Si}$-композита). Эта операция выполняется в вакууме путем нагрева пластин, полученных на первой стадии и предварительно покрытых подлежащими плавлению частицами дробленого кремния.

\section{3. Структурные и электрофизические свойства полученного материала}

Структура поперечного среза пластины SiC/Si-композита приведена на рис. 2. Микрофотография получена с использованием рентгеноспектрального локального микроанализа. Можно наблюдать слой самосвязанных кристаллитов $\mathrm{SiC}$ толщиной $\sim 40$ мкм, электросопротивление которого довольно высоко. Он совмещен с базовым слоем пропитанной кремнием углеродной фольги, сопротивление которого существенно ниже. Ниже дна этого слоя видны наплывы избыточного кремния, образующиеся при пропитке расплавом. Их сопротивление крайне низкое. На том же поле приведены профили концентрации кремния (слева) и углерода (справа) в условных единицах.

Для определения электрических характеристик полученных материалов были выполнены измерения температурной зависимости $R$ 2-зондовым методом на постоянном токе. Пластины каждого из типов материала размерами $60 \times 60$ мм размещались в полости П-образного графитового нагревателя. Внешние контакты из плотного графита выполнялись прижимными с промежуточными прокладками из пластичного графита. Измерения проводились в вакууме, для определения температуры образца использовалась термопара ВР 5/20. Следует отметить, что с тыльной поверхности каждый из образцов крепился к изолирующей пластине из монокристаллического сапфира, что означает, что электрические контакты осуществлялись лишь к фронтальной поверхности структуры. Результаты измерений приведены на рис. 3. Можно видеть, что, за исключением значительной разницы значений $R$, поведение сравниваемых материалов при

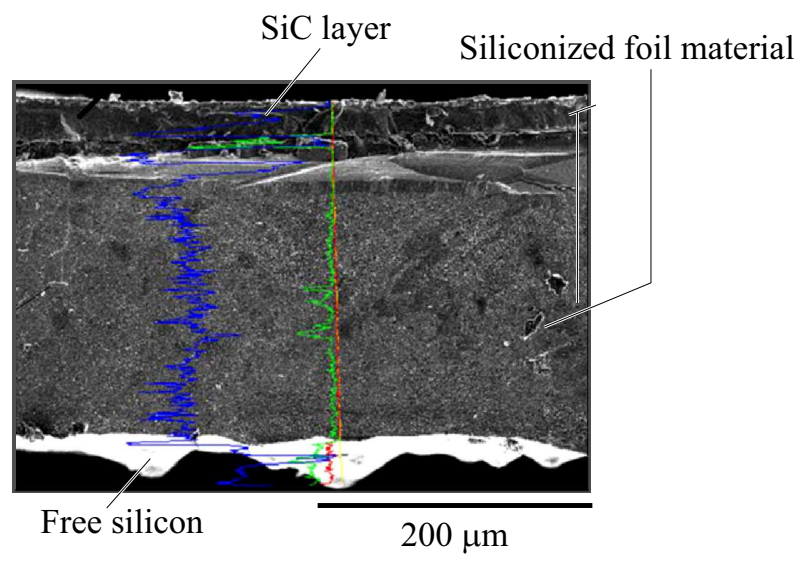

Рис. 2. Электронно-микроскопическое изображение поперечного среза пластины $\mathrm{SiC} / \mathrm{Si}$-композита. Обозначены концентрационные профили кремния (слева) и углерода (справа), полученные методом рентгеновского энергодисперсионного микроанализа. 


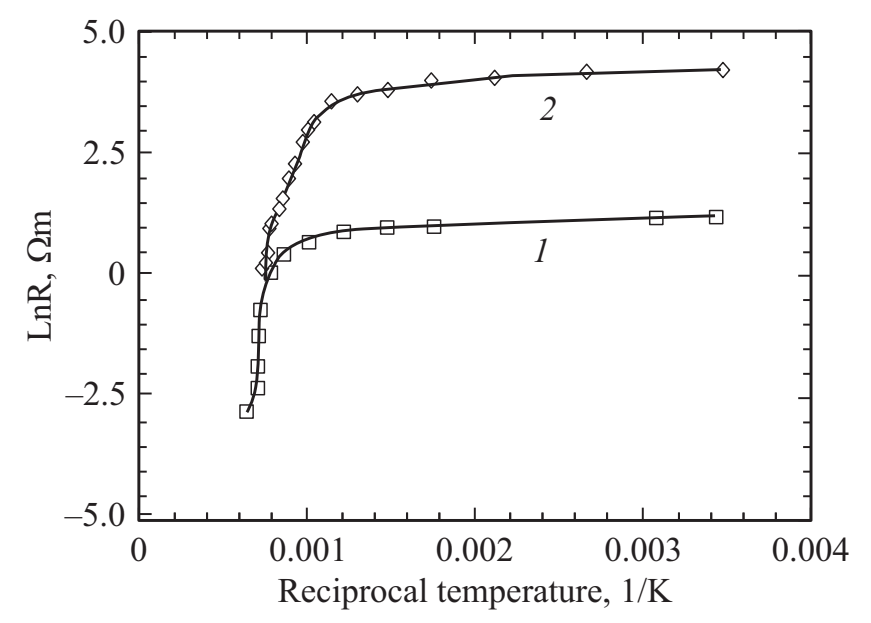

Pис. 3. Температурная зависимость электросопротивления двух типов полученного терморезистивного материала в координатах $\ln R=f(1 / T): 1-\mathrm{SiC} / \mathrm{C}$-композит, $2-\mathrm{SiC} / \mathrm{Si}$-композит.

нагреве достаточно сопоставимо. $\mathrm{SiC} / \mathrm{C}$-композит, не содержащий свободный кремний, начинает снижать значение $R$ при $T_{c}$, достигающей $\sim 1200 \mathrm{~K}$. SiC/Si-композит, содержащий фазу свободного кремния, демонстрирует падение $R$ при $T_{c}>900 \mathrm{~K}$.

Цифровая обработка данных по термочувствительности $B$ показывает значения $B=15550 \mathrm{~K}$ для $\mathrm{SiC} / \mathrm{C}$-композита (мы должны отметить, что указанное значение является минимальным среди полученных и зависит от толщины слоя, тогда как максимально измеренная величина составляет $85000 \mathrm{~K}$ ) и $B=11350 \mathrm{~K}$ для $\mathrm{SiC} / \mathrm{Si}$-композита. Таким образом, $\mathrm{SiC} / \mathrm{C}$ композит имеет преимущества перед $\mathrm{SiC} / \mathrm{Si}$-композитом, но не способен выдерживать нагрев на воздухе вследствие быстрого окисления слоя углеродной фольги с последующей фрагментацией остающегося слоя кристаллитов $\mathrm{SiC}$ на достаточно крупные, но хаотически распределенные по размерам пластины.

\section{4. Обсуждение результатов}

Детальное описание технологических операций, выполняемых при получении рассматриваемого материала, а также результаты исследования некоторых его характеристик приведены в ранее опубликованных источниках [13-16] и не требуют обсуждения. Наибольший интерес представляют данные для оценки термочувствительности $B$, значения которой кратно превышают известные. В связи с этим возникает вопрос о надежности использованного 2-зондового метода, не исключающего влияния паразитных термоэдс. на внешних контактах. Для подтверждения достоверности измерений, а также определения удельного электрического сопротивления мы провели дополнительные съемки температурной зависимости удельной проводимости $\sigma$ исходной угле- родной фольги и $\mathrm{SiC} / \mathrm{C}$-композита (рис. 4) в тех же условиях, но с использованием 4-зондового метода.

Исходная фольга демонстрирует типичную характеристику полуметалла (с удельным сопротивлением $\rho=0.0008$ Ом · см при комнатной температуре $T_{r}$, a $\mathrm{SiC} / \mathrm{C}$-композита (кривая 2) - полупроводника с $\rho=3$ Ом · см $\left(T_{r}\right), \quad T_{c} \sim 1200 \mathrm{~K}$. Полученные данные позволяют подтвердить надежность приведенных в предыдущем разделе результатов. Удельное сопротивление $\mathrm{SiC} / \mathrm{Si}$-композита при $T_{r}$ составляет $\sim 50 \mathrm{OM} \cdot \mathrm{cm}$, $T_{c} \sim 900 \mathrm{~K}$. Все упомянутые значения $\rho$ приемлемы для отнесения рассматриваемых материалов к классу полупроводниковых. Оптические характеристики полученных материалов в рамках данной работы не были исследованы, поскольку они не имеют прямого отношения к свойствам материалов для ТР.

В основе качественной интерпретации полученных результатов лежит понимание того, что подложка слоя $\mathrm{SiC}$ (сухая либо силицированная углеродная фольга) выполняет функцию консолидирующего фундамента и при температурах $<T_{c}$ ее электрическое шунтирование структуры крайне незначительно (рис. 4). При высокой температуре проводимости сухой подложки и структуры (кривая 2) выравниваются. Те же закономерности наблюдаются и при измерениях 2-зондовым методом (рис. 3). Таким образом, полученные зависимости могут интерпретироваться лишь в рамках модели двух независимых параллельных резисторов: слоя $\mathrm{SiC}$ и его подложки, а не использоваться для характеризации полупроводниковых свойств материала этого слоя.

Столь простая модель для описания достаточно сложного композиционного материала основана на следующих аргументах. Слой кристаллитов $\mathrm{SiC}$ является полупроводником $n$-типа проводимости с уровнем Ферми, расположенным вблизи дна зоны проводимости при температуре $<T_{c}$, и, следовательно, представляет собой гетероструктуру со слоем кристаллитов $\mathrm{SiC}$ с развитой

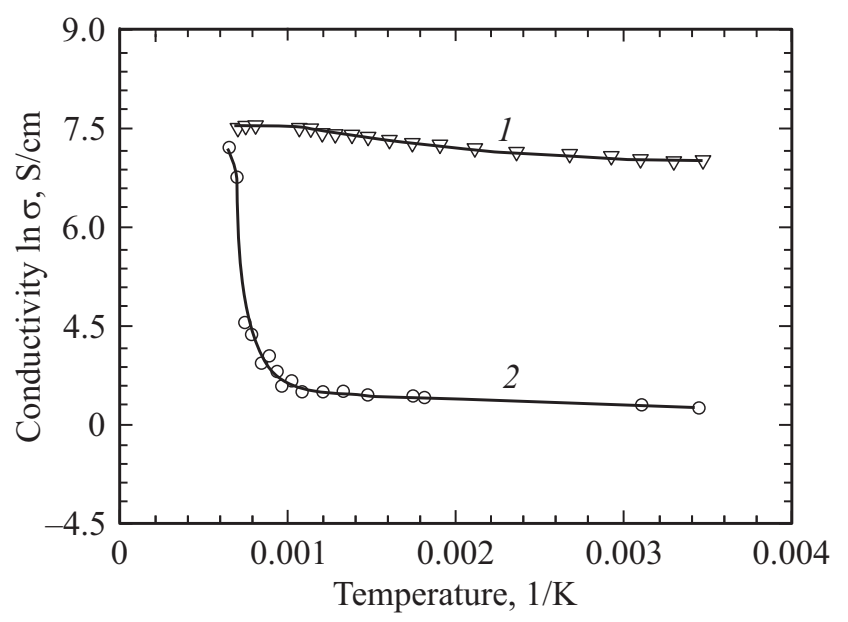

Рис. 4. Температурные зависимости удельной проводимости

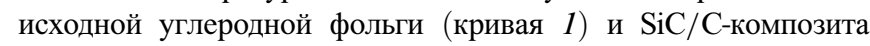
(кривая 2). 
поверхностью контакта $\mathrm{c}$ окружающей их матрицей кремния, прилегающего к слою силицированной углеродной фольги, с потенциальным барьером, равным, как минимум, ширине запрещенной зоны кремния. Высота такого барьера может составлять >1 эС при $T_{r}$ и снижаться до 0.4 эВ при $T>1200 \mathrm{~K}$ [17]. Этот барьер достаточен для эффективного разделения свободных носителей в рассматриваемых субсистемах.

Слой $\mathrm{SiC}$ контактирует по плоскости со слоем силицированной углеродной фольги (рис. 2), из чего следует, что их химические потенциалы равны и они имеют общий уровень Ферми. Выявленные экспериментально высокие значения термочувствительности $B$ не могут быть достигнуты лишь за счет снижения сопротивления монослоя полупроводника при увеличении его температуры. При увеличении температуры верхнего слоя каждого из композитов выше $T_{c}$ снижается переходное сопротивление между ним и нижним слоем, сопротивление которого многократно меньше, в результате чего резко увеличивется сила тока. Лишь этим обстоятельством обусловлены высокие значения термочувствительности.

\section{5. Заключение}

Терморезистивные свойства твердотельных материалов изучены настолько подробно, что рассчитывать на получение новых физических результатов в этой области достаточно сложно. Однако не исключены технологические изменения, повышающие эффективность известных устройств.

В данной работе рассмотрен способ синтеза самосвязанных кристаллитов $\mathrm{SiC}$ в структуре гибкой углеродной фольги (двуслойного композита). Получаемый материал обладает полупроводниковыми свойствами и может быть использован для изготовления ТР с чувствительностью $B=15550 \mathrm{~K}$ в температурном диапазоне $1200-1550 \mathrm{~K}$, но способных к использованию лишь в среде вакуума или инертного газа.

После проведения дополнительной операции его сквозной пропитки расплавленным кремнием получен композиционный материал, на основе которого изготовлены терморезисторы с диапазоном использования при температуре от 900 до $1450 \mathrm{~K}$, причем термочувствительность в этом диапазоне достигает значения $B=11350 \mathrm{~K}$, что значительно превосходит этот показатель для известных ТР. При этом они могут использоваться в среде воздуха. Следует отметить, что температура $1450 \mathrm{~K}$ ограничена использованием внешних контактов из металлических сплавов, склонных к образованию карбидов, но не свойствами карбида кремния.

Таким образом, реализован способ выращивания кристаллических слоев самосвязанного карбида кремния на поверхности графитовой фольги, позволяющий получать полупроводниковый композиционный материал в виде пластин значительной площади.
Выявленные у полученного материала полупроводниковые и термоэлектрические свойства позволяют рассчитывать на его применение в производстве приборов силовой электроники. Для доведения подобных ТР до промышленного уровня необходимо решить проблему внешних электрических соединений, устойчивых при эксплуатации, а также корпусного исполнения.

\section{Список литературы}

[1] А.Г. Шашков. Терморезисторы и их применение (М., Энергия, 1967).

[2] Ю.В. Зайцев. Полупроводниковые резисторы (М., Энергия, 1969).

[3] И.Т. Шефтель. Терморезисторы (М., Наука, 1973).

[4] Э.Д. Мэклин. Терморезисторы (М., Радио и связь, 1983).

[5] Ю.В. Зайцев. Полупроводниковые термоэлектрические преобразователи (М., Радио и связь, 1985).

[6] Э.Г. Бондаренко, Э.С. Чеботарева, А.Я. Олеск, Я.В. Малышева, Я.В. Павлоцкий. Патент RU2073274 (1997).

[7] J.C. Boivin, D. Thomas. Sol. St. Ionies, 5, 523 (1981).

[8] М.Н. Матвеев, Н.С. Липкина, М.А. Кожух. Патент SU1737523 (1992).

[9] E.G. Acheson. Patent US492767 (1893).

[10] A.V. Bazhenov, S.K. Brantov, A.A. Kolchin, N.N. Kuznetzov, V.N. Zverev. Composites Sci. Technol., 64, 1203 (2004).

[11] А.В. Романов, В.М. Пузиков, Е.П. Голубова, В.Н. Баумер, М.В. Добротворская. ФТП, 43 (5), 714 (2016).

[12] Th. Ullmann, H. Hald, A. Gúlhan, H. Schneider. High Temperature Ceramic Matrix Composites, 5, 519 (2004).

[13] S.K. Brantov, D.N. Borisenko, I.M. Shmyt'ko, E.A. Steinman. Recent Patents Mater. Sci., 6 (3), 253 (2013).

[14] С.К. Брантов. Патент RU2540668 (2015).

[15] C.К. Брантов, В.C. Ефремов. Патент RU144172 (2014).

[16] S.K. Brantov. Recent Patents Mater. Sci., 6 (2), 140 (2013).

[17] П.А. Киреев. Физика полупроводников (М., Высш. шк., 1969).

Редактор Г.А. Оганесян

\section{Thermoresistive semiconducting $\mathrm{SiC} / \mathrm{Si}$-composite material}

\author{
S.K. Brantov ${ }^{1}$, E.B. Yakimov ${ }^{2}$ \\ ${ }^{1}$ Institute of Solid State Physics, \\ Russian Academy of Sciences, \\ 142432 Chernogolovka, Moscow region, Russia \\ ${ }^{2}$ Institute of Microelectronics Technology, \\ Russian Academy of Sciences, \\ 142432 Chernogolovka, Moscow region, Russia
}

Abstract We suggest a method of growing self-bonded silicon carbide crystal layers on flexible carbon foil with additional impregnation of the obtained structure by silicon melt. The pilot thermistors for temperature range of $900-1450 \mathrm{~K}$ and thermal sensibility $11350 \mathrm{~K}$ were produced on the base of elaborated composite material. Structural and electrophysical characteristics of the mentioned material are investigated. 